\title{
Towards Scientific Economics
}

\author{
Mieczysław Dobija, Bartosz Kurek \\ Accounting Department, Cracow University of Economics, Krakow, Poland \\ Email: accountd@uek.krakow.pl,kurekb@uek.krakow.pl \\ Received February 1, 2013; revised March 14, 2013; accepted April 10, 2013
}

Copyright (C) 2013 Mieczysław Dobija, Bartosz Kurek. This is an open access article distributed under the Creative Commons Attribution License, which permits unrestricted use, distribution, and reproduction in any medium, provided the original work is properly cited.

\begin{abstract}
Economic thought still confronts with new problems arising together with the advancement of civilization. Economic matters are driving forces of human interactions so economics is expected to reveal why people, companies, banks, and governments behave in particular modes. B. Khumalo [1] is the author of a recent article in which he proposes a definition of economics that is adjusted to present times. Our article continues these considerations, since both terms: capital and resources have essentially changed their meaning. Though economics is still the study of a production and a distribution of goods, we recognize that labor of people and assets, which lead to the increase of concentration of capital in products is a driving force of economic activities as well. Essential explanations of a core triad: capital, labor and money accompany the proposed definition of economics.
\end{abstract}

Keywords: Theory of Economics; Scientific Economics; Science; Capital; Capital Growth Model

\section{Countable Resources and Measurable Capital}

\subsection{Three Types of Economic Means}

Economics deals with means, which are called "resources", whereas in fact they should be denoted as "economic means". It is clear that some of these means (e.g. raw materials) are processed in economy to usable goods and commodities with a help of other means (e.g. production machinery). The formulation of the economic theory requires a much deeper recognition of these mass "economic means". They are prime notions and therefore are used without precise definitions.

First of all there are three concepts that should be specified: resources, assets, and capital. Currently there is not any clear criterion for this fragmentation, nor any clear commonly accepted definition of any of these concepts; it is rather a collection of important ideas. For example, B. Khumalo [1, p. 603] refers to the definition of resources given by Vanderbilt University and American Economic Association. According to these institutions "Resources include the time and talent people have available, the land, buildings, equipment, and other tools on hand, and the knowledge of how to combine them to create useful products and services". This description includes merely everything, well maybe with an exception of such resources as coal or ore layers, stratums of oil, gas, and different minerals deeply under land. The above definition lists different "economic means" rather than explains (defines) resources.

The knowledge that enables societies to maintain better or worse equilibrium of the real economy comes from accounting and economics. The prime set of notions necessary for the creation of the economic theory includes: resources, assets, and capital. The concept of resources is just one of them. Each one is necessary but not sufficient. A number of fundamental differences exist between them, since e.g. capital is measurable whereas resources are only countable. Capital is abstract and homogenous, whilst resources are concrete, as it was originally stressed by Y. Ijiri [2]. That difference will be explained deeper in Section 2. For example, if one takes a look at any European football team from the resources point of view, one would see eleven players on the football field, whereas if one takes a look at the same team from the capital point of view, one would notice that these players represent their human capital, i.e. the total of their transfer values. Human resources are countable, as we can assign a number to each player and we can count them. On the other hand human capital is measurable, i.e. we can assign a measure of value to that capital.

Recognition of the true character of capital lasted for decades since its abstract nature and measurability, instead a simple countability, encountered many obstacles. 
The nature of capital has been examined by many authors, such as Ch. Bliss et al. [3] or B. Kurek [4, pp. 11-37], which is described in details in the subsequent section. Current state of knowledge enables one to claim that $c a$ pital is an ability of doing work. Capital is therefore an abstract category. As such, capital is embodied in assets. To understand the nature of capital one has to take into consideration thermodynamics. Thermodynamics, first of all explains that capital does not arise from nothing, and second of all that capital spontaneously diffuses, if not prevented from doing so.

The first printed book that includes some explanation of the relation between capital and assets, as well as a description of a system of periodical measurement of capital invested in business, was written by L. Pacioli [5] and was published in Venice in the year 1494. That book covered five topics and accounting was one of them. The accounting part was entitled "Particularis de Computis et Scripturis" ("About Accounts and Other Writings"). We can guess that at least from that time the measurement of the capital growth in business activities became a "common" skill. This knowledge is presently known as the two-dimensional double-entry accounting system. The essence of the double-entry recording is still a subject under examination by authors, such as Y. Ijiri [6] and M. Dobija [7], among others.

\subsection{The Basic Accounting Equation Mystery}

In order to show the relation between capital and assets, let us consider a very simple statement of financial position of a business. Assets of this firm include only a car (value of 40,000 USD) and a cash on hand (10,000 USD). The appropriate balance sheet of that company is presented in Table 1.

Both assets, i.e. a car and cash, first of all have their specific ability for performing work and second of all by definition assets have to assure a stream of inflows, so after a particular period one can expect that the total value of a business will be greater, despite the fact that the value of a car diminishes. It is the essence of assets. The aim of a firm is to increase the value of capital and this is an indispensable (sine qua non) condition of endurance. The main task of an accounting system is to measure periodical changes of capital - an income when capital increases and a loss when capital decreases. However, the unit of measure in that system has not yet been clearly understood. It is after all the unit of capital and

Table 1. Statement of financial position.

\begin{tabular}{rrcr}
\hline \multicolumn{2}{c}{ Assets } & \multicolumn{2}{c}{ Capital } \\
\hline Cash & $\$ 10,000$ & Owner's capital & $\$ 50,000$ \\
Car & $\$ 40,000$ & & \\
Total & $\$ 50,000$ & Total & $\$ 50,000$ \\
\hline
\end{tabular}

the notion capital was vague for centuries. Summing up - the value of assets is equal to the value of capital which is embodied in them.

In order to grasp the idea behind the unit of capital we have to notice the tandem of capital and labor. That tandem is a direct implication from the definition of capital. Capital is the ability of doing work. It is therefore the potential for doing work (e.g. the car in a garage). Labour process on the other hand is a transfer of this potential of accumulated capital to objects of work. Thus labor is a dynamic site of potential capital. One cannot perform any labor without having capital that was collected earlier. Therefore labor endows unit of measure to capital, so that capital is measured in units of labor. A. Smith [8] was right, when he wrote: "What is bought with money or with goods is purchased by labour, as much as what we acquire by the toil of our own body. That money or those goods indeed save us this toil. They contain the value of a certain quantity of labour which we exchange for what is supposed at the time to contain the value of an equal quantity". In physics labor is measured as the product of power and time of labor. Therefore the assignment of a position to an employee with a determined pay in fact allocates his/her potential power.

Assets are measurable only because capital is embodied in them. Capital being an economic measure fulfills general axioms, which are required by the mathematical concept of a measure. In a narrative language the measure can be described as follows:

Measure is a mapping $(m)$ which assigns positive real number $m(A)$ to an asset $A$ and it fulfills three axioms:

1) If asset $A$ does not exist, so $m(A)=0$ (measure is equal to zero).

2) If two assets $A$ and $B$ are separable, then $m(A$ and $B)$ $=m(A)+m(B)$ (measure is additive).

3) If $A$ is included in $B$, then $m(A) \leq m(B)$ (measure is monotonic).

Value determined by a free market exchange or value computed by cost accounting fulfills the above axioms, so they both can be discerned as a measure. Both mentioned measures have their significant role in economy and are known as an exchange value and a cost value.

Resources are the third basic notion worth consideration. That notion is the most uncertain concept among the three considered notions, nevertheless it is necessary in an economic language. The answer to the fundamental question "why resources are not assets" explains the concept of resources. They are not assets since resources are vague and not measurable by labor, which was the essential feature of the assets. Resources can be highly desirable. However, it is not clear if they are able to produce income in existing economic reality. Therefore we count them in natural units as tons or cubic meters. If for example, a company buys a land covering coal layers, this 
land becomes an asset, since the exchange value is assigned to it.

\section{What is Capital? Recent Solution for the Long Lasting Discussion}

Section 1 discerns capital as one of the three fundamental notions necessary for the description of scientific economics. The remaining two notions are: assets and resources, which may be confused with each other. Current state of knowledge allows one to claim that capital is an abstract, economic ability to perform labor. Originally that definition was given by M. Dobija in his late 90's papers. However, the term "capital" has been widely used in economics, accounting and finance for decades, centuries, and millennia. It is clear that even before economics was created (arbitrary acknowledging the publication of Adam Smith's 1776 book as the year when economics was established) the term "capital" was used frequently. The question whether the term "capital" was used before the invention of accounting is still open and cannot be answered easily. If Luca Pacioli's manuscript published in 1494 is discerned as the year when accounting was established, then we can say that the term "capital" is older. On the other hand, if one accepts the opinion that accounting is a system strictly designed for the measurement of capital, the question concerning the primacy of capital (accounting) over accounting (capital) becomes in fact the question on the primacy of an egg over a hen.

These hundreds of years, when the term "capital" has been used widely, have not led to the consensus among countless researchers concerning the true nature of capital. The result was a complete dissent. One of capital researchers, C. Bliss [9, p. vii], even wrote: "When economists reach agreement on the theory of capital they will shortly reach agreement on everything. Happily, for those who enjoy a diversity of views and beliefs, there is very little danger of this outcome. Indeed, there is at present not even agreement as to what the subject is about".

One of the researchers-S. Skrzypek [10]-thoroughly analysed the notion of capital in literature and distinguished five historical groups of views in which capital was understood similarly:

- ancient (notion of capital);

- medieval;

- technical-economic;

- transitional;

- social-economic.

S. Skrzypek [10, p. 2] notes that in the ancient and medieval times the notion of capital did not existed separately but in conjunction with notions of profit and interest rate. The notion of capital was strictly connected to the interest bearing amount of money. That was also noted by F. A. Fetter [11, p. 5], who provided readers with a detailed description of the usage of the word capitalis in medieval times. He wrote inter alia: "It made its appearance first in medieval Latin as an adjective capitalis (from caput, head) modifying the word pars, to designate the principal sum of a money loan". It is worth to note that L. Pacioli in his medieval Summa de Arithmetica, Geometria, Proportioni et Proportionalita defined capital as follows: "Capital means the entire amount of what you now possess" [12, p. 102].

The meaning of capital evolved throughout centuries. According to S. Skrzypek [10, pp. 11-12], the notion of capital started to include physical goods in the end of medieval times. That is also visible in one of the first written definitions of capital that was provided by Cotgrave in 1611 and quoted by F. A. Fetter: "wealth, worth; a stocke, a man's principal, or chiefe, substance" [13, p. 144]. F. A. Fetter [13, p. 144] also notes that this definition mixes worth (valuation) with material things in possession (substance). Such a misunderstanding is still present. W. Brzezin [14, p. 102] noticed that currently there are two points of view on capital: macroeconomic and microeconomic. The latter is consistent with the accounting understanding of capital, whereas the former one in fact relates to assets.

Technical-Economic notion of capital in its beginning included material items, but later it was expanded into intangible and personal goods. A. Smith balanced between technical-economic and social-economic notions of capital and - as commonly known - he distinguished three notions: land, capital and labor. At that time in England there were three social classes and capital was the domain of capitalists (owners of industries). A. Smith differentiated between circulating and fixed capital. According to A. Smith capital should bring revenue to its owner and if man's stock is used for consumption, it cannot be called capital anymore. S. Skrzypek [10, p. 57] noticed that during the dominancy of technical-economic notion of capital many misunderstandings between researchers were caused by a lack of agreement on the set of goods that could be included in capital. Some of researchers included also land or spiritual goods in that set.

Transitional notions were characterized by a joint collection of ideas between technical-economic approach and social economic approach.

According to S. Skrzypek [10, pp. 117-150] capital liberated itself from the matter in the social-economic approach. Capital became an abstract notion. J. B. Clark noticed that capital is eternal and indestructible $[10, \mathrm{pp}$. 127-128]. Y. Ijiri, the author quoted in Section 1, was also the one, who noted that capital is abstract, homogeneous and aggregated. There are, however, a number of differences between his approach and the one presented 
by authors of this article. The first major difference between these approaches is the understanding of the basic notions. Y. Ijiri [2, p. 61] uses the equation Resources = Capital and understands Capital as the shareholders' equity plus the long-term liabilities together with the current portion of long-term debt. Resources are understood as assets less the current liabilities (excluding the current portion of long-term debt). It can be said that Y. Ijiri offers an understanding for these notions from that statement of financial position approach. He is in fact using Assets in his equation, although he denotes them as Resources. To support our conclusion it should be said that the statement of financial position did not recognize all of the resources as assets, since some of them did not meet the recognition criteria stated in the definition of assets. The similar case applied to liabilities.

One the other hand we use the equation Assets = Capital and understand Capital as the abstract economic ability to perform labour, which in accounting can be measured by the sum of shareholders' equity (share capital: common and preferred share premium, retained earnings, etc.) plus all liabilities (short- and long-term). Assets in our approach are Resources, which value is determined by the concentration of Capital embodied in them.

In summary, no matter how capital is valued, the most distinctive feature of these approaches is the treatment of capital as the abstract, homogeneous notion.

\section{How Does Capital Grow?}

There are only two possible answers for the question stated in the heading of Section 3, which are:

- in a stochastic way;

- in a deterministic way.

Taking into consideration the current state of knowledge no other possible answer exists for the stated question. However, the final answer is not a straightforward one and requires a presentation of a capital growth model. That model describes the concentration of capital at a given point in time. In companies that continue their operations, capital grows according to the Equation (1) [15, p. 133] (Compare also [16-18]):

$$
C_{t 1, s, p, M}=C_{t 0} \times \mathrm{e}^{(p-s+M) \times \Delta t},
$$

where:

$C_{t 0}$ - the beginning concentration of capital [expressed in monetary terms] in the time moment $t 0$;

$C_{t 1, s, p, M}$ the ending concentration of capital [expressed in monetary terms] in the time moment $t 1$, which has been subdued to natural dispersion " $s$ " (risk), risk premium " $p$ " and a management variable " $M$ " through the time period $\Delta t$;

$s$ - dispersion variable (risk) [expressed as $1 /$ year];

$p$-risk premium, $p=E(s)$ [expressed as 1/year];
$M$-management variable [expressed as $1 /$ year];

$\Delta t$ - time period between time moments: $t 0$ and $t 1$ [expressed in years].

There are three factors that influence the concentration of capital. Two of them have a stochastic nature and one of them has a deterministic nature. Because of these factors capital will change its concentration in a given time period, i.e. it will increase or decrease it. Assuming that the concentration of capital determines the value of assets and assuming that capital is the general notion for equity as well as debt capital, the ex post rate of return on capital will equal to: " $R O A_{\text {ex post }}=p-s+M$ ". It is the $e x$ post rate of return on capital, and at the same time it is the capital growth (decrease) rate expressed in [1/year].

Such an ex post rate of return on capital may be calculated with the usage of different ratios. The general construction of such a ratio takes the form presented in Equation (2):

$$
R O A_{t 1, \Delta t}=\frac{A_{t 1}-A_{t 0}}{A_{t 0} \times \Delta t}[1 / \text { year }],
$$

where:

$A_{t 1}$ - the net cost of assets in the time moment $t 1$ [expressed in monetary terms];

$A_{t 0}$ - the net cost of assets in the time moment $t 0$ [expressed in monetary terms];

$\Delta t=t 1-t 0$ [expressed in years];

$R O A_{t 1, \Delta t}$ - the ex post rate of return on capital embodied in assets calculated in $t 1$ time moment realized in the time period $\Delta t$ [expressed in $1 /$ year ].

The difference between the cost of assets " $A_{t 1}-A_{t 0}$ " equals to the realized income in a considered period " $I_{\Delta t}$ ". The question which income figure from the income statement one should use is the open one, but it should approximate the result of normal operating conditions, i.e. the impact of extraordinary items should be eliminated. One proposal was presented by B. Kurek [18, p. 366]:

$$
R O A_{t 1, \Delta t}=\frac{I_{\Delta t}}{\frac{1}{2} \times\left(A_{t 0}+A_{t 1}\right) \times \Delta t},
$$

where:

$I_{\Delta t}$ - the realized income before extraordinary items in the period $\Delta t$ [expressed in monetary terms];

$A_{t 1}, A_{t 0}, \Delta t$ and $R O A_{t 1, \Delta t}$ as above.

Clearly the rate of return on capital and therefore the ending concentration of capital $\left(C_{t 1, s, p, M}\right)$ are random numbers for any chosen company. The first explanation is that no one can forecast a priori with $100 \%$ certainty the value of a company in the end of a period under consideration. That is an undeniable fact. If anyone could forecast with certainty the ending concentration of capital, no uncertainty and no risk would exist. The second explanation that stems from the capital growth model is that 
there are three variables that influence the concentration of capital, and two of them are stochastic. Therefore the ending concentration of capital is also a random number.

However, if the capital growth rate was a truly random number with an expected value of zero, no one would ever start his/her own business, as the economy would be a fair zero game. On the other hand, millions of people start their businesses and succeed. Millions also fail. Nevertheless it is a commonly accepted statement that economy is a non-zero game. There is a number of proof for that - one of them being companies listed on stock exchanges. These companies on average realize a positive rate of return. Evidence comes from various research. According to B. Kurek [18, p. 369] in each of the years from 2000 till 2007 the average annual capital growth rate in companies constituting S\&P 500 index (big companies) equaled between $6.19 \%$ and $11.59 \%$. In companies constituting S\&P 400 index (mid companies) that number equaled between $6.47 \%$ and $11.11 \%$. And in companies constituting S\&P 600 index (small companies) that number equaled between $3.40 \%$ and $8.89 \%$. The long-term pre-crisis (20 year period from 1986 till 2005) ex post average return on assets in companies constituting S\&P 1500 index was close to $8.57 \%$ [19, p. 386].

The outcome of the research quoted above and the outcome of similar research (Compare also [4]) may suggest that the capital growth rate is not a truly random number, because on average it is above zero. Therefore one can say that on average capital grows in small, medium and large companies.

Capital growth rate can be computed in different areas, including, but not limited to:

- return on assets calculations;

- stock exchange and risk premium calculations;

- human capital and minimum wage calculations (Compare [17]).

\section{Fundamental Laws that Determine Economic Environment}

\subsection{Laws of Nature that Drive Our World}

"Within metaphysics, there are two competing theories of Laws of Nature. On one account, the Regularity Theory, Laws of Nature are statements of the uniformities or regularities in the world; they are mere descriptions of the way the world is. On the other account, the Necessitarian Theory, Laws of Nature are the "principles" which govern the natural phenomena of the world. That is, the natural world "obeys" the Laws of Nature" [20].

Laws of Nature that are discovered and formulated but not necessarily proved are called fundamental. To some laws the constants are accompanied. For instance the law of gravity is accompanied with constant $\mathrm{G}$ called the Galactic as expression of a belief that it is obeyed every- where. A. Einstein showed that the velocity of light is also the constant of Nature. Fundamental laws are simple and deep and nothing can be correctly explain without them. As P. Atkins [21, p. v] writes in the preface to his book "Among the hundreds of laws that describe the universe, there lurks a mighty handful. These are the laws of thermodynamics, which summarize the properties of energy and its transformation from one form to another". The mentioned author reminds that thermodynamics is not only about steam engines because it is almost about everything including processes of life.

The first and the second law of thermodynamics do shape significantly economic environment. Without both of them we could not measure periodic income and understand nature of profit as well. The double-entry bookkeeping comes directly from the first law; particularly its part, which informs that ability for doing work does not arise from nothing. Therefore accounting system uses the double entry recording as the core rule. The second law allows, among others, to explain a concept of the fair pay as an amount that covers the spontaneous and random diffusion of employee's human capital. Together with the discovered economic constant of potential growth, the second law, as the thermodynamic arrow of time, sheds a light on the important concept for economics as uncertainty and flow of time. Both thermodynamics laws participate in the model of capital.

F. Knight [22] tried to explain a difference between uncertainty and risk. He pointed out that there was a relation between an income and uncertainty. The later one is undeniably a consequence of the second law. It is an essential part of the model of income that stems from the model of capital growth. It should also be mentioned that risk is not a source of profit.

The law of the greatest significance for both physics and economics is the law of the least action. A researcher of MIT, D. Dalrymple [23] claims: "At least for me, the least action perspective explains all known physics as well as the origin of our universe, and that sure is deep and beautiful". This author explains also that: "Action is a strange quantity, in the units of energy multiplied by time. A principle of least action does not explicitly specify what will happen, like an equation of motion does, but simply asserts that the action will be the least of any conceivable actions. In some sense, the universe is maximally efficient. To be precise, the action integrated over any interval of time is always minimal". Similarly action in the economic consideration is the product of capital and time of its labor. Such economic categories as concept of cost, concept of optimizations, among others, are deeply related to the least action principle. A cost as defined by E. Burzym [24, pp. 107-109] is the least outlays necessary for accomplishing a given task. What is over is a loss. Cost control tends to keep costs on the right level 
not allowing for losses. We humans choose ways, which lead directly to our aim saving time and energy. Optimization should assure that some planned aim will be achieved at the least costs and time.

Thus, the least principle action seems to be a fundamental for Nature, and therefore we also meet its manifestations in economics. Moreover, when conducting economic activities people strive for saving actions in order to gain expected profits. The gain of a value added is an engine of economic activities.

\subsection{The Category of Autonomous Systems}

A human being with its three, naturally generated, components (body-mind-spirit) is hardly recognizable. M. Mazur [25, p. 437], the originator of the autonomous system theory, pointed out a new way of thinking in this matter. The mentioned author explains that: "In contrast to the common practice of observing individuals in order to generalize human behavior, the author's main idea is to consider the human being as a particular case of the autonomous system". This approach allows us to apply the principle, according to which every general statement applies to all particular cases. M. Mazur points out that the autonomous system is able to control itself, and is able to preserve its ability to control itself. The last condition requires the existence of an organ that maintains functional equilibrium of energetic and information processes, i.e. homeostasis. In order to control itself the autonomous system requires organs for reception and accumulation, both: energy and information. M. Mazur [25, p. 440] made an analysis of information processes in autonomous systems from the physical point of view. He examined potentials, conductance, and energy flow, which elucidate physical nature of such phenomena as memory, emotions, reflections, intuition, consciousness, thinking, motivation, and decision making. With regard to character, the author considers level of character, dynamism of character, and broadness of character. His research (conducted purely from the point of view of physics) shed some light on perception of all autonomous systems, which tend to maintain their existence. States, firms, humans, animals belong to the class of autonomous systems. In these cases the own business of every being is the dominating, overwhelming motivation of life and actions.

The aim of an accounting system that respects the duality principle is to measure a periodical economic performance of business activities. It is hopefully the income, as it is a common knowledge that firms in most cases, on average, earn profits. Therefore such basic ratios as: ROE (return on equity) and ROA (return on assets) should be examined in comparison to some standards values. These are usually: $8 \%$ for ROA and slightly more for ROE. The research conducted by B. Kurek [4], who used large sets of data leads to the conclusion that yearly average value of ROA is pretty stable and close to $8 \%$. If that is so, we may claim that the invested capital grows according to the compound interest formula. Since capital grows constantly we can write the expression $C_{t 1, p}=C_{t 0} \times \mathrm{e}^{p \times \Delta t}$, where $p=0.08$ [1/year]. This formula introduces the law of exponential growth of capital invested in business activities. Applying a wider interpretation we may conclude that the game with Nature is the positive non zero sum game. As was explained earlier the Nature enables growth on the level close to $8 \%$ per year. Significant number of research papers also suggests that the average return on human capital (fair minimum salaries and wages) is close to eight percent per year. Therefore we may speak about the significant law-the law of exponential growth of capital, which is an important feature of reality.

\subsection{Fundamental Laws that Form Economic Framework}

Supply and demand are the two important economic categories. Economists examined behaviors of prices in relation to the variables of supply and demand, which resulted in some essential conclusions. The law of demand states that with a high degree of probability we can claim that the quantity of goods, commodities and services demanded is in reversal proportion to their prices. Some paradoxes, such as the Veblen one and the Giffen one are also known and described thoroughly in the economic literature. The recognition of the law of demand as one of the fundamental economic principles is essential, since this rule determines a significant feature of reality. Individuals conducting their businesses on the market have to respect this law, treating it as a feature and a constraint of reality. Table 2 presents a list of fundamental principles shaping economic environment.

After having enlightened the economic environment a bit, which is a scene for economic theories, we will try to say a word about the economic equilibrium. First of all it has to be said that the equilibrium is a feature of an existing autonomous system. With the usage of autonomous systems theory it can be said that the equilibrium state can be clearly definable as the continuous maintenance of feedbacks among subsystems forming the entire system.

There is a number of well described and explained, adequate theories that refer to the equilibrium of business firms. Historical accounting data is easily accessible and such data feeds theories so that they can fulfill expectations. Moreover, firms usually have got strong management systems, and productivity of human resources is constantly under control.

In case of the whole economy similarities and relations with autonomous systems are not so perfectly precise as 
Table 2. List of fundamental principles shaping economic environment.

\begin{tabular}{|c|c|c|}
\hline & The fundamental economic principles & Patterns in physics and cybernetics \\
\hline 1 & $\begin{array}{l}\text { Duality principle, which is the principle of equality of the beginning value of assets and capital } \\
\text { embodied in them. In conclusion capital does not arise from nothing, but it flows through a labor process. }\end{array}$ & $\begin{array}{l}\text { A rule of conservation of energy and } \\
\text { the first law of thermodynamics. }\end{array}$ \\
\hline 2 & $\begin{array}{l}\text { Every concentration of capital is subdued to a random and spontaneous diffusion. Other formulation: } \\
\text { "Existence and maintenance of human capital requires a loss of a part of outlays". }\end{array}$ & The second law of thermodynamics. \\
\hline 3 & $\begin{array}{l}\text { Law of exponential growth of capital invested in business activities. It results from an economic } \\
\text { constant of potential growth. The average growth rate is close to } 8 \% \text { per year. }\end{array}$ & Lack of a relevant principle. \\
\hline 4 & $\begin{array}{l}\text { Successful economic actions (capital } \times \text { time) must be conducted in accordance to the least action principle. } \\
\text { Cost is an economic category and determines outlays, which are indispensable for the planned aim. }\end{array}$ & The least action principle. \\
\hline 5 & $\begin{array}{l}\text { The law of demand: it is highly probable that a quantity of a commodity demanded is in a reversal } \\
\text { proportion to a price of that commodity. Supply and demand establish an exchange value. }\end{array}$ & Lack of a relevant principle. \\
\hline 6 & $\begin{array}{l}\text { Autonomous systems strive for the maintenance of existence. They act in their own business. This } \\
\text { principle determines perception and understanding of organizations, states, businesses and individuals in } \\
\text { the economic considerations. }\end{array}$ & $\begin{array}{l}\text { Cybernetics. Theory of autonomous } \\
\text { systems. }\end{array}$ \\
\hline
\end{tabular}

in the case of business companies. A strong control of resources is often not achievable in the economy. The maintenance of homeostasis is often abused by wrong state laws, which results from weak institutional and intellectual capital. Some decisions are often out of control of the government. For example the growth of population can be too quick in comparison to the growth of capital embodied in natural, institutional and technical resources. These matters are difficult for effective control, since the respective decisions belong to citizens, and not to the government. Thus, the maintenance of the four-main resources (natural, human, technical, and institutionalintellectual) close to equilibrium level is a continuous political struggle. The achieved state is a result of a behavior of population, of a political action, and of other factors. It is not only an issue of economic theories.

Economics however can feed economists with some functional ratios useful in controlling the equilibrium. For example the labor productivity ratio $\mathrm{Q}$ defined as the quotient of the real GDP and the total of compensations (salaries, wages and all remunerations) $\mathrm{W}$ is one of the most effective measures of economic progress. It is explained in papers by M. Dobija [16] and M. Jedrzejczyk [26]. The more the $\mathrm{Q}$ ratio increases, the better the state of economy. Citizens are better off, since compensations increase, as well as the amount of credit accessible to them. The minimal salary (wage) can also increase if the $\mathrm{Q}$ grows.

\section{The Triad: Capital-Labor-Money}

\subsection{Labor as a Dynamic Facet of Capital}

The concept of labor is closely related to the concept of capital. Capital embodied in objects, such as human resources, has its potential for doing work. During a work human capital is transferred to the object of work. Manufacturing, teaching, taking care of children are the sim- plest examples of labor, which can be perceived as transfers of human capital. These transfers concern capital embodied both in humans and in all assets, such as: buildings, tools, devices, and raw materials. These assets came into existence as a result of human work. The capital which is transferred does not lose any fraction during transfers called labor. The situation is different though in the case of a spontaneous diffusion of human capital by heat. Both ways of transfers are important in economic considerations. The transfers called labor are a subject of management controls. However, the spontaneous diffusion of capital should be taken into regard when computing a minimum pay.

Besides a qualitative determination of the labor process, we need to recognize the methods for the measurement of labor. A general approach, well known from physics, enables to measure the labor $L$ according to the formula:

$$
L=F \cdot s \cdot \cos \alpha,
$$

where:

$L$-labor [expressed in joules];

$F$ - shifting force [expressed in newtons];

$s$-distance [expressed in meters];

$\cos \alpha$ - the cosine of an angle between a direction of a shift and a direction of the acting force [no unit].

However, the formula presented in the Equation (4) is a simplification. Before an individual can yield a force, the human capital has to be concentrated earlier. An individual can use force since he/she possesses potential (ability of doing work) that was collected earlier. It is called a human capital. Therefore we shall introduce another well known formula:

$$
s=v \cdot \Delta t
$$

where:

$$
\begin{aligned}
& v \text {-velocity [expressed in } \mathrm{m} / \mathrm{s}] \\
& \Delta t \text { - time of labor [expressed in } s] \text {. }
\end{aligned}
$$


Substituting $s$ in the Equation (4) with Equation (5), we can write an Equation (6) in the form of:

$$
L=F \cdot v \cdot t \cdot \cos \alpha,
$$

The product of force and velocity is usually denoted as power $P$ [expressed in watts]. Therefore Equation (7) can be written:

$$
L=P \cdot t \cdot \cos \alpha,
$$

Astonishingly the above considerations are commonly applied in practice. Let us consider a list of positions in a company. Each of them is assigned a salary. In fact this list assigns a power coefficient to an employee. It is easily visible when this salary is divided by the highest one. This fraction represents the power coefficient $P$. Variable $\Delta t$ denotes a period of time of during which work is performed. The last factor $\cos \alpha$ - as explained in [27] denotes a degree of consistency between intention of the employee and management aims. In economics the $\cos \alpha$ takes any figure from the interval $[-1 ;+1]$ and represents a sort of labor utility coefficient. Let us note that hooligans work with $\cos \alpha=-1$ destroying existing useful assets. On the other hand, a competent employee working under self and management control has a coefficient of $\cos \alpha=+1$.

Labor is a transfer. It is the transfer of energy to object of work in physics. Labor is the transfer of employee's human capital to products in the economy. Therefore in physics a unit of labor is also a unit of energy. It implies that in the economy a monetary unit, which is a unit of capital, is the labor unit as well. It truly has to be so, since we get money for accomplished work. At this mo- ment we have just discovered a basic contradiction. If a money unit is a labor unit and a labor process is the transfer of energy/capital, then no institution should be allowed to create money, since this activity contradicts the fundamental law of energy conservation. Since, as commonly known-economic theories admit the existence of such institutions (e.g. central banks), economies suffer destructive disorder, deficits, and unemployment. Figure 1 explains how labor creates money in the correctly conducted economy.

\subsection{Labor Makes Money}

Once labor is accomplished, two economic categories are created: products (in which the capital transferred by labor is concentrated) and work receivables, which are the accounting record of the value of work done, as is illustrated on Figure 1. It is the essence of the moneygoods economy, which can be capitalistic or socialistic, free market or not. A flow of human capital through work, as presented in the body of Table 3, obeys the double-entry recording, which guarantees that neither capital, nor money (work receivables), arise from nothing.

The above ruminations lead to the conclusion, which is of the greatest importance for economics. The first conclusion concerns labor-labor is a transfer of capital and therefore labor is always self financing. If a work is accomplished by an employee and an adequate amount of capital is concentrated on a designed location, this is the end of a story. The only thing that should now be done is the accounting record of the work receivables for the

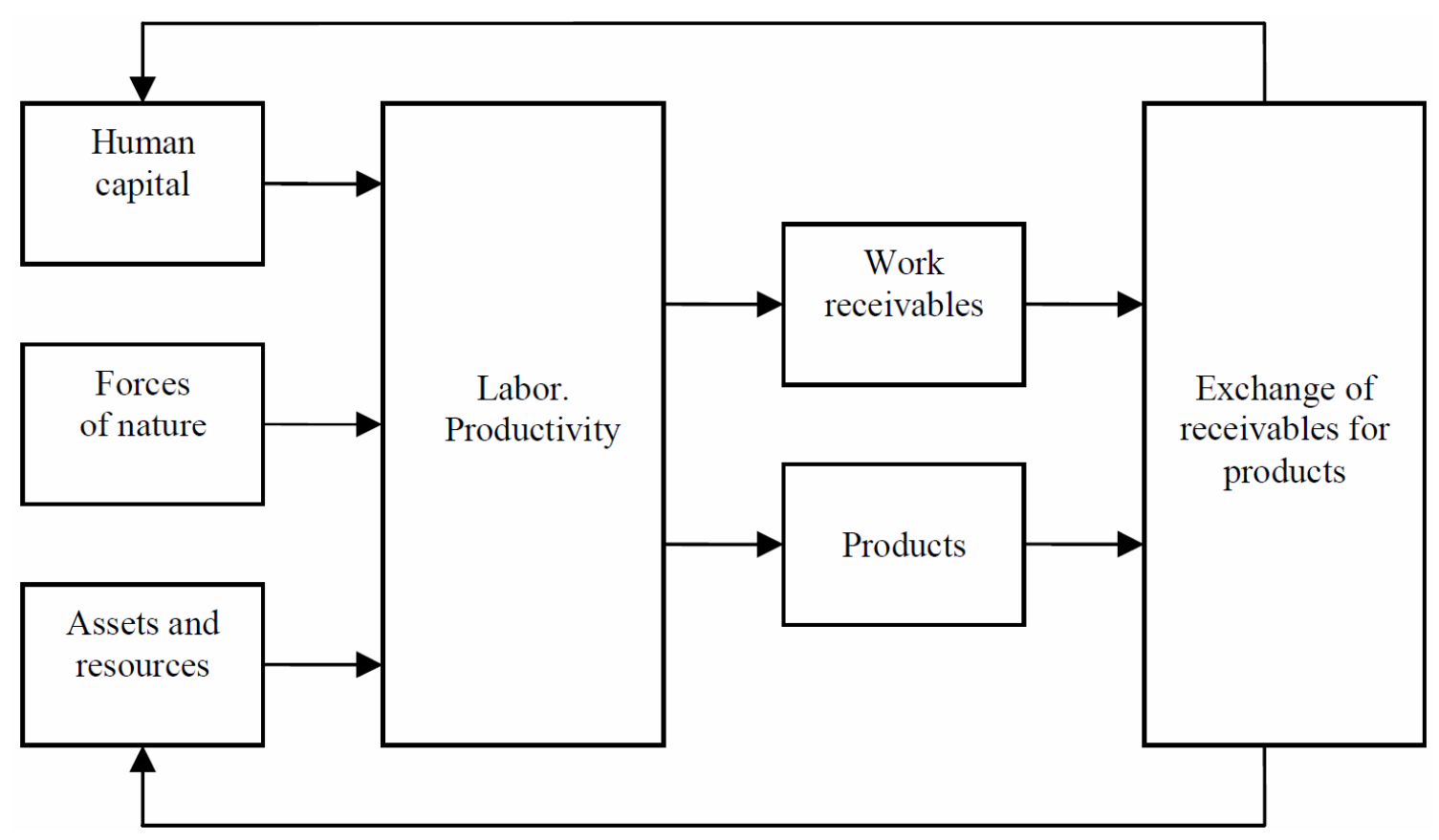

Figure 1. Labor process and work receivables as money. 
Table 3. A simplified description of human capital transfers by labor and renumeration for work.

\begin{tabular}{cccc}
\hline DR & Employee & DR & Employer \\
\hline & Transaction 1. By labor an employee transfers his human capital to products. \\
2. Employee's human capital & 1. Products (object of work) \\
Transaction 2. Registration of work receivables for labor done. & 2. Pay liabilities (payables)
\end{tabular}

DR Employee's bank account CR

Transaction 3. An employer makes a payment to the employee's bank account.

3. Worker's wage receivables as

liabilities of a bank

3. Pay liabilities (payables)

Transaction 4. A worker exchanges his wages for products.

4. Decrease of worker's wage receivables in a bank
4. Decrease of products' account employee who has performed the work. But it is merely just an accounting record, which follows the labor, and it is not a real capital transfer.

In case of a private sector of economy employers have to cover the cost of labor by the inflows from sales. On the other hand, in the case of a public sector the employer (the state administration) do not need to have inflows from taxes in order to pay for labor. The state administration only has to confirm the accomplishment of labor by accounting entries (in Table 3 these are entries number: 2 and 3). By such an entry work receivables are recorded on the credit side of employee's commercial bank account. It is the essence of the money-goods economy. The total amount of salaries and wages in public sectors is limited and determined by the ratio of labor productivity Q as is explained in [17]. As commonly known the present state of affairs is far away from the proposed system. Governments organize various tax systems in order to collect funds, which are used to pay for labor made in the public sector. That is a severe charge for each economy. Therefore the present, poorly organized, economies work as "scarcity engines" as it was named by D. Rushkoff [28, p. 244]. The scheme of correctly organized economy has already been presented in the paper [16]. The correct solution for the current problem requires the adjustment of Central Banks' practices to respect the fundamental law of capital conservation. First of all each Central Bank should stop the creation of money from nothing. Second of all Central Banks should become payees for the public sector salaries, wages and other compensations.

Moreover, the description of labor process in economy with the usage of an accounting scheme leads to the conclusion that this is in fact the money-goods economy with clearly defined money unit.

\section{The Modern Definition of Economics. A Discussion and a Proposal}

\subsection{Accounting and Economics Complementary Relationships}

Economy is explained and levered by two complementary disciplines: accounting and economics. Accounting measures the growth of capital in business activities, as well as maintains companies in economic equilibrium. That equilibrium is indispensable for the endurance of a firm. Some authors assume that the theory of national income and GDP measurement belongs to accounting. In such a case all professional, periodically accomplished and mandatory economic measurements, which are indispensable for contemporary economies and policies, are subjects of accounting. Therefore besides the definition of economics it is worth to present our understanding of accounting. Much in this subject has been done by R. Mattessich [29, p. 210], an accounting theorist, who determined accounting as " $a$ discipline concerned with the quantitative description and projection of the income circulation and a wealth aggregates by means of a method based on a set of basic assumption". R. Mattessich lists 18 assumptions, which are necessary and sufficient conditions for the existence of this science, such as duality, valuation, monetary values, entities.

We recognize accounting as a theory and a practice of retrospective and prospective measurement of the economic variables, particularly invested capital, which characterize economic unit activities. The measurement is accomplished in accordance to a constant set of accounting principles, which among others, determine applied measures and modes of valuation. The dominant principle is the duality principle that manifests itself in double-entry recording of economic transactions. 
Examining the ways how accounting, which was characterized briefly by L. Pacioli more than five centuries ago in a printed book published in 1494, became a discipline deeply engaged in maintaining the equilibrium in economic units, and the discipline, which essentially serves government agencies in "orchestrating" economy, we have come up to the conclusion that accounting fulfills expectations well. According to us that is the only correct assessment. The knowledge that that capital is abstract and embodied in assets was present in accounting from the very beginning, i.e. from $15^{\text {th }}$ century as least. The lack of recognition of this fact can be seen as one of the major reasons of some delays in economics in respect to the category of capital. Furthermore, the concept of a cost and the cost accounting theory are subdued to the least action principle, as it was written earlier. The formulation of the definition of economics requires a decision whether a constant periodical measurement of income created in business units belongs to economics or not. If it does not (we agree with this opinion), then the accounting theory is a parallel knowledge to economics, despite the fact that capital is their common notion.

\subsection{A Proposal}

After having clearly determined relations between accounting and economics we will try to explain the nature and the task of economics. We refer to a recent consideration that has been made by B. Khumalo [1, p. 597], who underlined the importance of a definition: "A definition, both for the beginning reader and the experienced reader, gives a subject matter direction and scope". It is a right opinion.

The referred author starts his considerations from well known opinions expressed by Ronald M. Ayers and Robert A. Collinge that "Economics studies the allocation of limited resources in response to unlimited wants" and that "Economics examines how to make choices well". The author shows drawbacks and weaknesses of this simple statement, and step by step goes nearer and nearer to his own definition that includes a special resource-knowledge. B. Khumalo is precise in his deliberations, and he also raises the problem of resources and their definition. He writes [1, p. 602]: "We can easily understand land, labor, and capital as resources". However, the material (not abstract) understanding of capital is a very old one and obsolete. This is not a creative perception of capital that lasts from a very beginning of economics, with an exception of economists, who perceived capital as a fund, despite the fact they could not explain factors that affected capital.

As it was explained earlier, capital is an abstract notion and denotes ability of doing work. Similarly labor cannot be deemed as a resource but should be understood as the flow of capital from a source, for instance human capital, to a product. Technically humans can be conceived as resources since humans are countable. Labor on the other hand is measurable. Moreover capital, which is in fact a potential category, is measurable in labor units. B. Khumalo [1, pp. 597 \& 606] modifies Paul Samuelson's definition: "Economics is the study of how societies use scarce resources to produce valuable commodities and distribute them among different people" into: "Economics is the study of how humans use knowledge to identify resources and use these scarce resources to create, using knowledge, commodities and distribute them among people". The author applies the above definition to the economic thought.

The newly introduced definition underlines the role of knowledge (in identifying resources and producing commodities). It is curious that this knowledge is mainly from fields of physics, chemistry, electronics and techniques. Traders and entrepreneurs are also involved. The author writes further [1, p. 604]: "Understanding that it is knowledge the main driver of economics, one can sum up the African problems as not respecting the laws of knowledge, the laws that allow the knowledge base to grow in a society, when knowledge is treated for what it is, the primary resource and primary commodity". Let as stop for a while and put our attention to Burkina Faso in Africa. It is commonly known that cotton produced in Burkina Faso has the best quality. However, farmers in that country suffer poverty since the USA generously donates American producers. That results in very low market prices for cotton. Is it an economic problem subdued to the above definition? Europe conducts common agriculture policy and assures high donations to each hectare of soil. Europe exports grain. How does it influence prices of grain in Ukraine? Do these prices cover the cost of production in Ukraine?

We doubt that B. Khumalo's views in respect to Physiocracy and in respect to the input of Nature on economic value are correct. We agree that the accomplished labor is a factor of growth. However what is a source of labor? It is the human capital of a human being. Is it possible to bring up a person without the Sun energy and the phenomenon of photosynthesis? F. Quesnay's view is correct although not complete. A farmer collaborates with photosynthesis. On the other hand, a worker does not. However, both of them are under the influence of the second principle of thermodynamics, therefore they have to work. B. Khumalo is right that labor is necessary to create value since this labor by nature is the process of value transfer to products. Last but not least: without the Nature an economy would not be the positive non zero sum game.

We hope that economics in the twenty first century will deal with the essential agendas, which have not been solved yet. Economics should help in answering such 
Questions, as: how can a government conduct balanced money-goods economy? What is the fair pay that preserves worker's human capital? What are the forces that drive the trend of exchange rate? What is a fair price of agriculture products? How can a government maintain stability of economic system?

Economics has to leave the constant misunderstanding of three terms: capital, labor, and money. These notions form the fundamental triad. Economics deals with the measurement and therefore can generate tools for accountability in accordance to equivalent exchanges.

The proposal for a new definition of economics is as follows:

Economics is a set of the economic disciplines that explain how money-goods economy works. These disciplines provide tools, which enable fair and equivalent accountability between economic agents. Economics identifies and recognizes abstract capital embodied in human, natural, and institutional-intellectual countable resources, as well as in economic units, and produced goods and commodities. Economics examines the movement (flow) of capital between different resources and the factors and the rates of growth. Furthermore, economics formulates reasonable models and algorithms of equivalent exchanges which determine fair prices and fair compensations. Economics identifies synergetic effects that manifest themselves in phenomena of capital accumulation and growth.

\section{Summary and Conclusion}

The aim of the article was to formulate a definition of economics, which involves the correct understanding of capital (as the abstract ability of doing work) and all related categories adjusted to the modern comprehension of capital. Considerations leading to a formulation of an adequate definition revealed scientific fundamentals of economics. They are similar to fundamentals of all sciences. They are fundamental laws of Nature and mysterious numbers called constants. We have showed the laws supporting economic thought as well as a recently discovered number: the economic constant of potential growth. It leads to a conclusion that economics stands in front of a great change, since the first law of thermodynamics is a universal one, thus capital cannot be created, but only transferred by labor. It is the main conclusion. The proposed definition of economics is supported by a deeper recognition of resources, assets and capital and involves primarily conducting the money-goods economy and creating tools for accountability between economic agents.

\section{REFERENCES}

[1] B. Khumalo, "Defining Economics in the Twenty First
Century," Modern Economy, Vol. 3, No. 5, 2012, pp. 597-607. doi:10.4236/me.2012.35079

[2] Y. Ijiri, "Segment Statements and Informativeness Measures: Managing Capital vs. Managing Resources," Accounting Horizons, Vol. 9, No. 3, 1995, pp. 55-67.

[3] Ch. Bliss, "Capital Theory and the Distribution of Income," North-Holland Publishing, Oxford, 1975.

[4] B. Kurek, "A Hypothesis of the Deterministic Risk Premium," Doctoral Dissertations, No. 10, Wydawnictwo Uniwersytetu Ekonomicznego, Kraków, 2011.

[5] L. Pacioli, "Everything about Arithmetic, Geometry and Proportion," 1494.

[6] Y. Ijiri, "The Beauty of Double-Entry Bookkeeping and Its Impact on the Nature of Accounting Information," Economic Notes, Vol. 22, No. 2, 1993, pp. 265-285.

[7] M. Dobija, "Timeless Greatness and Significance of the Double-Entry Accounting," Management and Business Administration Central Europe, Vol. 4, No. 117, 2012, pp. 3-22. doi:10.7206/mba.ce.2084-3356.19

[8] A. Smith, "An Inquiry into the Nature and Causes of the Wealth of Nations," 1776.

http://www.econlib.org/library/Smith/smWN2.html.

[9] C. Bliss, "Capital Theory and the Distribution of Income," North-Holland Publishing Company, Amsterdam, 1975.

[10] S. T. Skrzypek, "The Notion of Capital in Literature," 1939.

[11] F. A. Fetter, "Reformulation of the Concepts of Capital and Income in Economics and Accounting," Accounting Review, Vol. 12, No. 1, 1937, pp. 3-12.

[12] Y. Ijiri, "The Foundations of Accounting Measurement," Scholars Book Co., Houston, 1967.

[13] F. A. Fetter, "Capital, Interest, and Rent. Essays in the Theory of Distribution," Sheed Andrews and McMeel, Inc., Kansas, 1977.

[14] W. Brzezin, "General Accounting Theory," 1995.

[15] M. Dobija, "Fair Value as a Criterion of Truth in Economic Theory," In: W. Adamczyk, Ed., Pursuit of Truth in Economics, Akademia Ekonomiczna w Krakowie, Kraków, 2006, pp. 125-150.

[16] M. Dobija, "Abstract Nature of Money and the Modern Equation of Exchange," Modern Economy, Vol. 2, No. 2, 2011, pp. 142-152. doi:10.4236/me.2011.22019

[17] M. Dobija, "Labour Productivity vs. Minimum Wage Level," Modern Economy, Vol. 2, No. 5, 2011, pp. 780787. doi: $10.4236 / \mathrm{me} .2011 .25086$

[18] B. Kurek, "An Estimation of the Capital Growth Rate in Business Activities," Modern Economy, Vol. 3, No. 4, 2011, pp. 364-372. doi:10.4236/me.2012.34047

[19] B. Kurek, "The Risk Premium Estimation on the Basis of Adjusted ROA," In: I. Górowski, Ed., General Accounting Theory. Evolution and Design for Efficiency, Academic and Professional Press, Warsaw, 2008, pp. 375392.

[20] N. Schwartz, "Laws of Nature," 2013. http://www.iep.utm.edu/lawofnat/.

[21] P. Atkins, "Four Laws that Drive the Universe," Oxford 
University Press, New York, 2007.

[22] F. Knight, "Risk, Uncertainty, and Profit," Houghton Mifflin Company, Boston, 1921. http://www.econlib.org/library/Knight/knRUP7.html

[23] D. Dalrymple, "The Principle of Least Action," 2012. http://edge.org/response-detail/11722

[24] E. Burzym, "Measurement and Profitability Evaluation of State-Owned Enterprises," Państwowe Wydawnictwo Ekonomiczne, Warszawa, 1971.

[25] M. Mazur, "Cybernetics and Character," PIW, Warszawa 1976.

[26] M. Jedrzejczyk, "Labor Productivity Parity vs. Trend of
Exchange Rate," Modern Economy, Vol. 3, No. 6, 2012, pp. 780-785.

[27] B. Kurek, "Accounting as a Stimulant of Culture's Development" Theoretical Issues in Accounting, Vol. 24, No. 80, 2004, pp. 38-59.

[28] D. Rushkoff, “Open Source Currency,” In: J. Brockman, Ed., What is Your Dangerous Idea, Wydawnictwo Smak Słowa and Wydawnictwo SWPS Academica, Sopot-Warszawa, 2008, pp. 244-245.

[29] R. Mattessich, "Critique of Accounting, Examination of the Foundations and Normative Structure of an Applied Discipline,” Quorum Books, Westport, 1995. 